\section{INVERSION OF THE UTERUS: REMOVAL BY LIGATURE: DEATH.}

\section{By N. COATS, Esq.}

[Read before the South Wales Branch, June 1855.]

Tre following history of a case of inversion of the uterus is more or less interesting. I need not say that happily is more or less rare; but when they occur, they are very formidable, and the displaced organ should be immediately returned; for the longer the case is left, the greater will be the difficulty, from the diminished size of the os uteri. Cases are recorded where the organ becomes spontaneously inverted after the birth of the child; but they more generally arise from too great traction being made on the chord. In this case, it was produced by the midwife putting the woman on her feet, and making her blow in a bottle, to expel the placenta.

CAsE. June 4th, 1853. Leah Morgan, aged 44, had had six children, the last fourteen years since. She had a good labour, but the placenta did not come away immediately. The midwife got her out of bed, and put her in the erect position, to blow in a bottle, which brought the placenta away without any interference. She was then put back to bed, and had in two hours very severe after pains. She then took castor oil, and in an hour the bowels were moved. She then found in the night-chair, for the first time, a large swelling protruding through the os externum. She sent for the midwife, who could not tell what it was. Mr. Jackson, the late surgeon to the Tredegar Works, was sent for. He tried to return it, but could not: he again came in a few hours, and tried, but did not succeed. She was seen by Mr. Jackson and Mr. Davis four days after the delivery : they attempted to return the uterus, and she considered the reduction was accomplished. Three months elapsed before she conld resume her household duties; she then menstruated, and continued regular the following six months. At that time she was depressed in spirits by losing her child, and by unfortunately having her house robbed at the same time. From that time to the date of $\mathrm{my}$ attendance (fourteen Jears), she never menstruated, but suffered attacks of flooding every three or four days; the longest time during which she was free being a fortnight. She had at intervals a thickish white and sometimes a watery discharge, with constant pain in the loins and hips. The stomach was very irritable, with sickness and loss of appetite. For the last three years of her life, I attended this patient, and gave her the various preparations of iron and injections. I always found her sitting up; but on June 3rd, when passing her house, I was called in, and found her in bed, suffering from profuse hæmorrhagic discharge. Her countenance was perfectly anæmic; the pulse was small and imitable; and she altogether looked like a person suffering from some organic disease. I requested a vaginal examination, and found a tumour of the size of a moderate pear, and of that shape, with the base downwards. I thought at first that it was a polypus; but, on tracing it up the vagina, I could find no os uteri. I then suspected it was an inverted uterus. I gave her some castor oil, as the rectum was much distended.

June 4th. I used the speculum vaginæ, but did not find it of much service. I examined her very carefully per vaginam, and found the ragina a complete cul de sac. I now felt certain from that circumstance, and from the history of the case, which I now learned, that the tumour was an invarted uterus. I then wrote to Dr. Lever, of Guy's Hospital, relating to him the case. He advised me to remove it by ligature.

June 8th. I passed a whipcord ligature around the apex of the tumour, with a Gooch's canula In tying it, it gave her but little pain. Her countenance was very pallid; the pulso was 116, and very mall. I gare her the following pill.

R Pulv. opii gr. i. Station sumatur.
I aleo prescribed the following mixtur.

B Sodæ sesquicarb. 3 iss.

Tincturm opii $3 j$.

Spiritûs stheris yitr. $\mathbf{j}$.

Aquæ menthø piper. 3 viij. $\mathbf{M}$

Fiat mistura cujus sumat cochlearias ij ampla 4 tis horis.

June 9th. She stated that great pain came on an hour or so after applying the ligature. The pill, however, quieted her very much; and she slept all night, and some hours to-day. There was no tenderness nor pain on prewsure on the bowels. The pulse was 120; she was rather thirsty. I tightened the ligature, and ondered her to continue the mixture, and to take nothing but tea and slope. The bowels had not been moved; she made water, but with a little difficulty. She appeared in good spirits.

June loth. The patient had passed a good night, but complained of a great watery discharge. The pulse wae about 100 ; she had little pain in the left iliac region. She had passed urine, but the bowels had not been moved. I ordered her to take immediately an ounce of castor oil. The mixture was repeated. The ligature was tightened, which at first gave her pain, but soon subsided. On the whole, I thought her doing well.

June 11th. Fourth day. I found her asleep. At 5 P.r. the pulse was about 100; the skin cool; the bowels had been moved; she was rather thirsty. She stated that she had severe pain after the ligature was tightened on the previous day, but was relieved by the mixture. She complained of pain in the iliac regions, especially the left, extending down the thighs to the knee. There was no tenderness of the bowels. I tightened the ligature; this but little increased the pain. The mixture was continued as before.

June 12th. Fifth day. She slept moderately well. The bowels had been acted on twice, and she had made water without difficulty. The pulse was about 90 . She still complained of pain, especially in the left iliac region. The bowels were not tender. I ordered her to have a litkle mutton broth and a little boiled rice and milk. The liga ture was again tightened, which rather increased the pain. The mixture was continued.

June 13th. Sixth day. She had slept well, but looked very pallid, and felt weak. The bowels had been moved; and she had passed urine. The pulse was 90 . She had pain in the iliac regions down to the knees. There was no tenderncss of the bowels. She had taken a little broth, but had no desire for food. I tightened the ligature an inch: the discharge was rather offensive and bloody. She complained of the ligature for a fer minutes, and then entered into conversation freely.

June 14th. Seventh day. The pulse was 100; the symptoms as yesterday. I ordered a little wine and genorous diet. The ligature was tightened.

June 15th. Eighth day. The symptoms were as yestermday. She was directed to continue as before. The ligature was tightened, which produced great pain, but it soon abated. She appeared moderately well.

June 16th. Ninth day. She had slept badly; she had a severe rigor at six o'clock in the morning, which bated until eleven o'clock. There was pain in the bowels, increased on pressure; the pulse was about 100; the skia hot and dry; she was very thirsty. The wine was diminished. The bowels were relieved. The ligature was again tightened; the discharge was offensive, and considerable in quantity, tinged with blood. I ordered the mixture to be continued, and the following pill to be taken at night:

$R$ Calomelanos gr. $i$.

Pulveris opii gr. ss. $M$.

Fiat pilula horâ somni sumonda.

Warm water was directed to be applied to the rulva.

June 17th. Tenth day. She had slept better; and the feverish symptoms had subsided. The pulse was 95; tho tenderness was remored. The ligature was tightened; the discharge was offensive, and rather considerablo.

June 18th. Eleventh day. She was about the ame as jorterday. She slept moderately well, but fainted when in the night-chair. The ligature was again tightened, which 
are conidamble pain. There could not be much more of the nterus to cut through.

Jnne 19th. Trodfth day. She had slept moderately well, bat complained of pain in the borrels, which had not been eponed since the night of the 17th; they were also slightly pollen and tender. She passed but little urine, and had rigor in the afternoon. The tongue was dry ; the pulse about 80 ; the countenance very cadaverous; but she appeared pretty cheerful, and had taken a little wine and Froth twice this day. I passed a catheter, and drew off three ounces of urine, and ordered one ounce of castor oil to be taken immediately. Wine and water, and good broth, are also prescribed; and the mixture was continued; the discharge was less, and the ligature could not be further tightened.

June 20tb. Thirteenth day. She had slept moderately; but her bowels had not been moved, nor had she made water. She complained, when moved, of great pain; both hips were swollen and discoloured, pitting on pressure; the collular tissue seemed inflamed over those parts. The pulse was 100 ; the tongue dry; the countenance very pallid. I ordered an ounce of castor oil, and passed a catheter. Half a pint of port wine, and three grains of sulphate of quinine were ordered to be taken daily. I brought the fundus of the uterus to the os externum; it was very nearly cut through.

June 21st. Fourteenth day. The bowels had been reliered four times; she had made water, but complained of great pain when touched or moved. The swelling on the hips was less; but the cellular tissue seemed inflamed over the abdominal parietes, extending over the lower portion of the sternum, to the left side of the thorax. This part had a yellow appearance; it pitted on pressure, and was hotter than the adjacent parts. She could bear to be pressed on the abdomen pretty well. The tongue was very dry, and the pulse 106. She was suffering from low ferer. The ligature broke to-day at the bottom of the canula. I remored the canula, and with a little traction brought down the uterus through the os externum, and tied what remained to be cut off, which was about the size of a pencil. I ordered the following:

R Tincturæ opii $m$ x.

Spiritús ammoniæ aromat.

Tincturæ larandulæ comp. à 3 ss.

Aquæ menthæ sature $3 i$. ss. M.

Fiat haustus horâ somni sumendus.

June 22. Fifteenth day. The patient did not sleep, but was free from pain. The tongue was very dry. She took little nourishment; she did not complain of the ligature. There was a slight dark discharge. The uterus was at the os externum. She complained when touched over the sternum and epigastrium; she appeared very low indeed. A draught of liquor ammoniæ acetatis and camphor mixture were ordered to be taken every two hours.

June 23. Sixteenth day. The pain in the abdomen was severe. She was not able to take any nourishment. I gave her a dose of calomel and opium. She died at 7 A.M. in the morning.

REMARKs. I cannot make many remarks on this case ; but I presume that the ligature is the most judicious way to remove the uterus when it is inverted and cannot be replaced. I should like to be informed, in case of a recent case of inversion not returnable, what would be the best time after the accident to tie the uterus? Perhaps some of our friends who have had cases will give their experience, and state the earliest time at which the ligature has been applied after the accident.

I would also with diffidence suggest that, in case of the operation being necessary, the ligature be applied around the uterus sufficiently tight to compress its vessels, so that if possible a plug might be formed in them as in tying an artery, without carrying it to the extent of removing the organ, as the object for the operation is to prevent the constant hamorrhage which is occurring, as in this case, every three or four days.

I believe this is nearly the only case on record of a wo-

man living fourteen jears with an inverted uterus, which is one reason why it ought to be published; another reason is to put practitioners on their guand when they have cases of this character to return it at once. I can assure you that the gentlemen who were callod in were men of great experience, and they must have found it a difficult thing to accom: plish, or would hare succeeded. I beliere chloroform would be very useful.

Sirhowy Iron Works, Monmonthshire, June 1855.

\section{ASSOCIATION DTIFLIGHTCE.}

\section{NOTICE REGARDING THE PAYMENT OF} SUBSCRIPTIONS.

The Laws declare-

Firs:-That on the 1st of January of each year, the annual subscription of one guirea becomes due in advance.

SECOND:-That "if any member's subscription remain unpaid tecon:- That it shall become due, the MEDICAL JouRNar and other publications of the Society shall be withheld from such member till his arrears be paid."

Circulars are now being issued to all who are in arrear, or of whose payment no notice has been received.

\section{ANNUAL MEETING.}

The Anndar Meetiva of the Protinctax Medical aND SURGICAI Association wILL BE heLD AT York ON THE 15TH AND 16TH OF AUGUST. Particulars regarding the arrangements will be published in the Jodrisa next week.

\section{BRANCH EXPENSES:-OFFICIAL NOTICE FROM THE} SECRETARY OF THE IANCASHIRE AND CHESHIRE BRANCH.

"Manchester, 293, Oxford Street, July 17th, 1855.

"SIr,-At the late anniversary meeting of the Lancashire and Cheshire Branch of the Provincial Medical and Surgical Association, the following resolution was unanimously passed:

"That this meeting strongly urge the members of the ceneral Association to pass a law at York, that each Branch shall defray its own expenses.'

"I beg that you will take the necessary steps to bring this resolution before the Annual Meeting of the Association to be held at York.

"I am, etc., Jorn Hatros, Hon. Sec.

“J. R. Cormack, M.D., Sec. to the Prov. SYed. and Surg. Assoa.

\section{BRANCH MEETINGS TO BE HELD.}

SAXE OT BRAXCH.

Birminghay and Mid-

LAND Coontres.

[Annual Meeting.]

Shropshire.

[Annual Meeting.]
De. Thurs., July 26, 4 P.x.

Friday, Aug. 3, 1 P.M. 